\title{
An Experimental Didactic Space Of Rainwater Harvesting Contributes For Agrarian Science Teaching In The Brazilian Semiarid
}

\author{
Alisson Jadavi Pereira da Silva ${ }^{1}$, Jilcélio Nunes de Almeida ${ }^{2}$ \\ ${ }^{1,2}$ Instituto Federal Baiano, Campus Senhor do Bonfim. \\ Email: alisson.silva@ifbaiano.edu.br, jilcelioalmeida@ifbaiano.edu.br \\ Received: March $13^{\text {th }}, 2017$ \\ Accepted: May $14^{\text {th }}, 2017$ \\ Published: June $30^{\text {th }}, 2017$ \\ Copyright (O2016 by authors and Institute \\ of Technology Galileo of Amazon (ITEGAM). \\ This work is licensed under the Creative \\ Commons Attribution International \\ License (CC BY 4.0). \\ http://creativecommons.org/lic enses/by/4.0/ \\ (c) (1)(3) Open Acees

\begin{abstract}
:
In regions where people live far from water sources it was seen specific demands and characteristics little addressed in the usual literature of agrarian education in Brazil. Some factors make it difficult to integrate teaching-research-extension in education the semiarid region, such as use of technology packages derived from research originating to meet specific demands and different from those observed in rural areas, or foreign literature adaptation. Therefore, this case study presents some results of the implementation of rainwater harvesting for agrarian science teaching at the Instituto Federal Baiano, Campus Senhor do Bonfim. Two cisterns with $52 \mathrm{~m} 3$ (volume unit) were built to rainwater harvesting from the roof of the educational institution, which is located far from ground and surface water source. The experimental didactic space enabled to start a process of solving local problems and change our approach to what we teach. In 2015, after implementation of the experimental didactic space, it was possible to insert practical classes covering issues not found in popular literary in the education process of students. The experimental didactic space enabled execution of experiments and extension activity.
\end{abstract}

Keywords: education, agrarian science, production cistern.

\begin{abstract}
RESUMO
As demandas da sociedade rural do semiárido, localizadas longe de fontes hídricas, apresentam características específicas, pouco abordadas nas usuais literaturas do ensino agrícola do país. O uso de pacotes tecnológicos prontos na academia, oriundos de resultados de pesquisas realizados para atender demandas específicas e diferentes daquelas percebidas em zonas rurais do semiárido, ou de adaptação de literatura estrangeira, torna difícil integrar ensino-pesquisa-extensão na didática escolar desta região. Diante disso, o presente estudo de caso apresenta alguns resultados da implantação de uma unidade didática-experimental com captação e uso de água da chuva para o ensino de Licenciatura em Ciências Agrárias do Instituto Federal Baiano, Campus Senhor do Bonfim. Duas cisternas, cada uma com volume de $52 \mathrm{~m}^{3}$, foram construídas a fim de armazenar água captada no telhado da instituição de ensino, que se situa distante de fonte hídrica subterrânea e superficial. A unidade montada possibilitou iniciar um processo de resolução de problemas locais e de mudança da abordagem curricular. No ano de 2015, após a unidade montada, foi possível integrar ao processo formativo dos alunos: realização de aulas práticas abordando conteúdos não encontrados na literatura do curso; execução de experimentos visando resolver problemas locais; integração com a comunidade externa por meio da realização de cursos, oficinas e dias de campo.
\end{abstract}

Palavras-Chave: educação, ciências agrárias, cisterna de produção.

\section{INTRODUÇÃO}

As demandas por conhecimento da sociedade rural do semiárido, localizada longe de fontes hídricas superficiais e subterrâneas, apresentam características específicas, pouco abordadas nas usuais literaturas do ensino agrícola do país. O uso de pacotes tecnológicos prontos na academia, oriundos de resultados de pesquisas realizados para atender demandas específicas, ou de adaptação de literatura estrangeira, torna difícil integrar pesquisa e extensão ao interesse de comunidades rurais localizadas em regiões de baixo acesso a água.

Ações formativas, quando dirigidas a atender demandas da sociedade local, exigem a prática integrada de pesquisa e extensão, desde o momento inicial de percepção do problema, até 
a difusão da provável resolução do problema percebido. No âmbito da extensão, [1] em trabalho realizado junto a agricultores familiares do semiárido baiano, concluíram que o diálogo, o diagnóstico e o planejamento estratégico participativo devem ser feitos junto a agricultores, pois as metodologias tradicionalmente utilizadas (transversal e de pacotes prontos), apresentam resultados limitados.

Ao perceber as diversas demandas apresentadas pela sociedade rural do semiárido, os educadores e educandos se deparam com uma discrepância entre a demanda social e a demanda acadêmica. A primeira pode ser atendida com tecnologias sociais, pesquisa básica e de campo. A segunda, entretanto, exige experiência prévia demonstrada por titulação acadêmica e quantitativa de indicadores científicos. Neste sentido,

\section{MATERIAIS E MÉTODOS}

A unidade didática-experimental foi instalada no campus Senhor do Bonfim do Instituto Federal de Educação, Ciência e Tecnologia Baiano, em Senhor do Bonfim-BA. O clima do local é semiárido, sendo a precipitação média anual de $574,8 \mathrm{~mm}$ com déficit hídrico elevado durante todo o ano, sendo mais intenso nos no âmbito acadêmico, as propostas de projetos nem sempre são avaliadas por conhecedores da demanda social rural do semiárido. [2] afirmam que a compreensão adequada dessa temática dependerá, cada vez mais, da capacidade de a academia nacional redirecionar seu olhar multidisciplinar para o vasto grupo de agricultores até então "invisíveis" na base da pirâmide social do campo.

Diante disso, o presente estudo de caso apresenta alguns resultados da implementação de uma unidade didáticaexperimental de captação e uso de água da chuva, visando iniciar um processo de resolução de problemas locais e de mudança da abordagem curricular no ensino de Licenciatura em Ciências Agrárias do Instituto Federal Baiano, campus Senhor do Bonfim, estado da Bahia.

meses de setembro a janeiro. O campus encontra-se localizado distante de fontes de água superficial e subterrânea.

Em um complexo Laboratorial construído no ano de 2011, haviam bicas instaladas, porém sem qualquer tipo de aproveitamento da água proveniente do telhado. Assim, uma área foi delimitada e a área de duas cisternas foi definida para captação de água da chuva, conforme Figura 1.

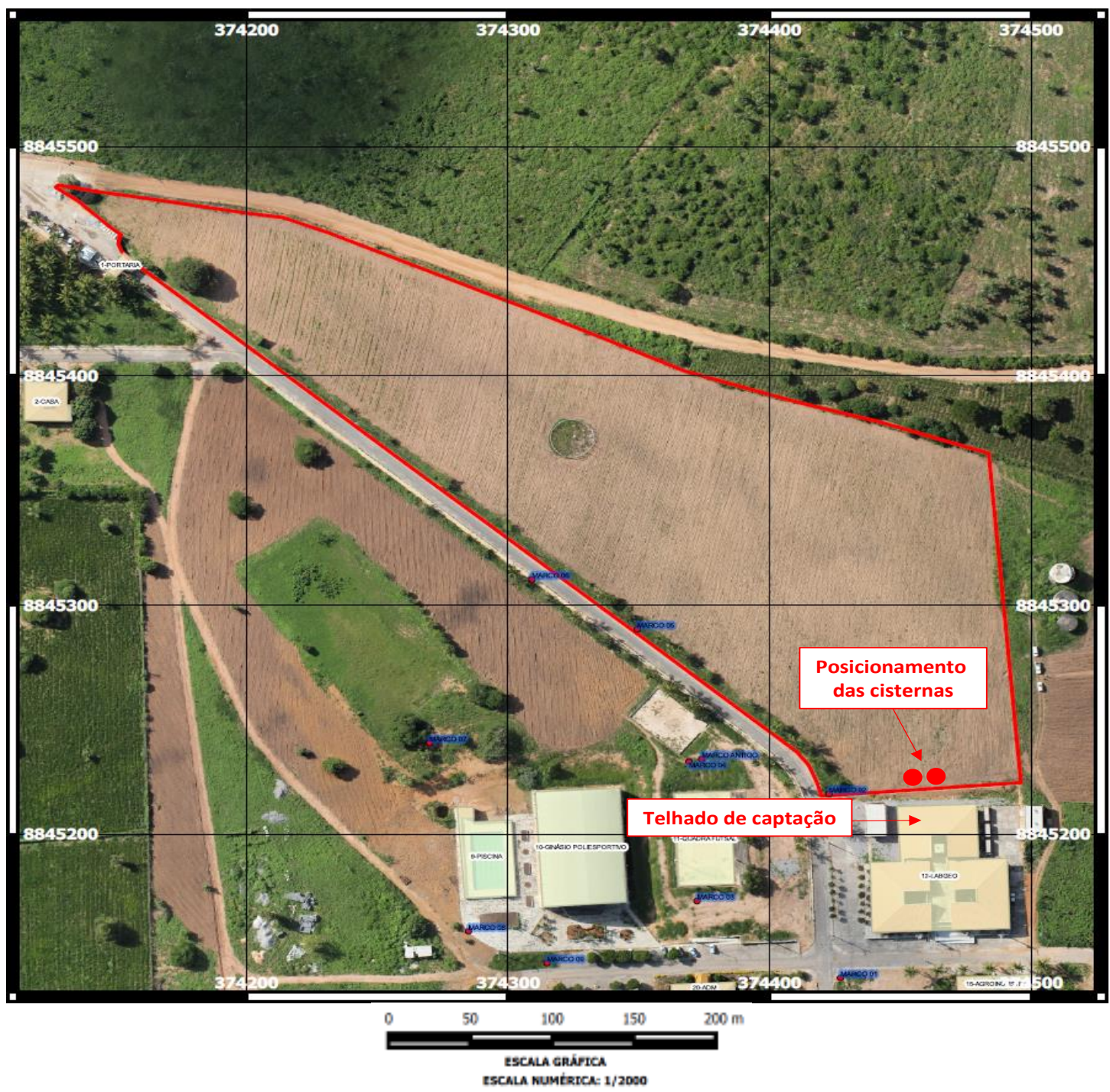

Figura 1: Posicionamento das cisternas no Campus Senhor do Bonfim do IF Baiano e visão do telhado utilizado para captação de água da chuva.

Fonte: Elaboração: LABGEO-Campus Senhor do Bonfim. 
Para construção das cisternas, duas áreas circulares foram demarcadas com auxílio de um barbante e dois tornos. Aplicou-se cal para dar destaque a marcação dos círculos que foram definidos com diâmetro de $8 \mathrm{~m}$. Com os círculos marcados e destacados, utilizou-se de uma retroescavadeira para escavação do buraco a uma profundidade de $1,8 \mathrm{~m}$ (Figura 2A). Seguiu-se para confecção das placas das paredes, traçadas a uma proporção de 9 latas de areia para 1 saco de cimento, com dimensões de $0,5 \times 0,6$ $\mathrm{m}$ e espessura de $0,04 \mathrm{~m}$, envergadas a $0,01 \mathrm{~m}$ (Figura 2B). As placas da cobertura foram traçadas a uma proporção de 7 latas de areia para 1 saco de cimento, formatadas em cone com base de 0,5 m, altura de 2,8 m e espessura de 0,08 m (Figura 2C).

$\mathrm{O}$ fundo do buraco escavado foi nivelado, onde aplicou-se concreto sob traço de 12 latas de areia para 01 saco de cimento e 08 latas de brita 0 . Uma armadura circular construída com ferro
1/4" foi posicionada acima do primeiro concreto. Após posicionamento da grade uma nova concretagem foi realizada.

Foram construídos caibros para sustentação das placas da cobertura moldados por uma forma cônica (Figura 2D). Os caibros foram traçados a uma proporção de 6 latas de areia para 5 latas de brita 0 e 1 saco de cimento, sendo que no centro des ta estrutura foram centralizadas duas barras de ferro de 5/16". Os caibros foram ancorados em uma coroa de $1 \mathrm{~m}$ de diâmetro e $0,1 \mathrm{~m}$ de espessura (Figura 2G). A coroa foi posicionada sobre uma coluna central moldada em tubo PVC de $150 \mathrm{~mm}$ com $2,8 \mathrm{~m}$ de altura. As bicas já se encontravam instaladas na estrutura predial. A área total do telhado utilizado captação de água da chuva foi $2.400 \mathrm{~m}^{2}$. A água captada no telhado foi conduzida até as duas cisternas por meio da conexão de tubos de PVC de $150 \mathrm{~mm}$ às bicas já existentes no local.
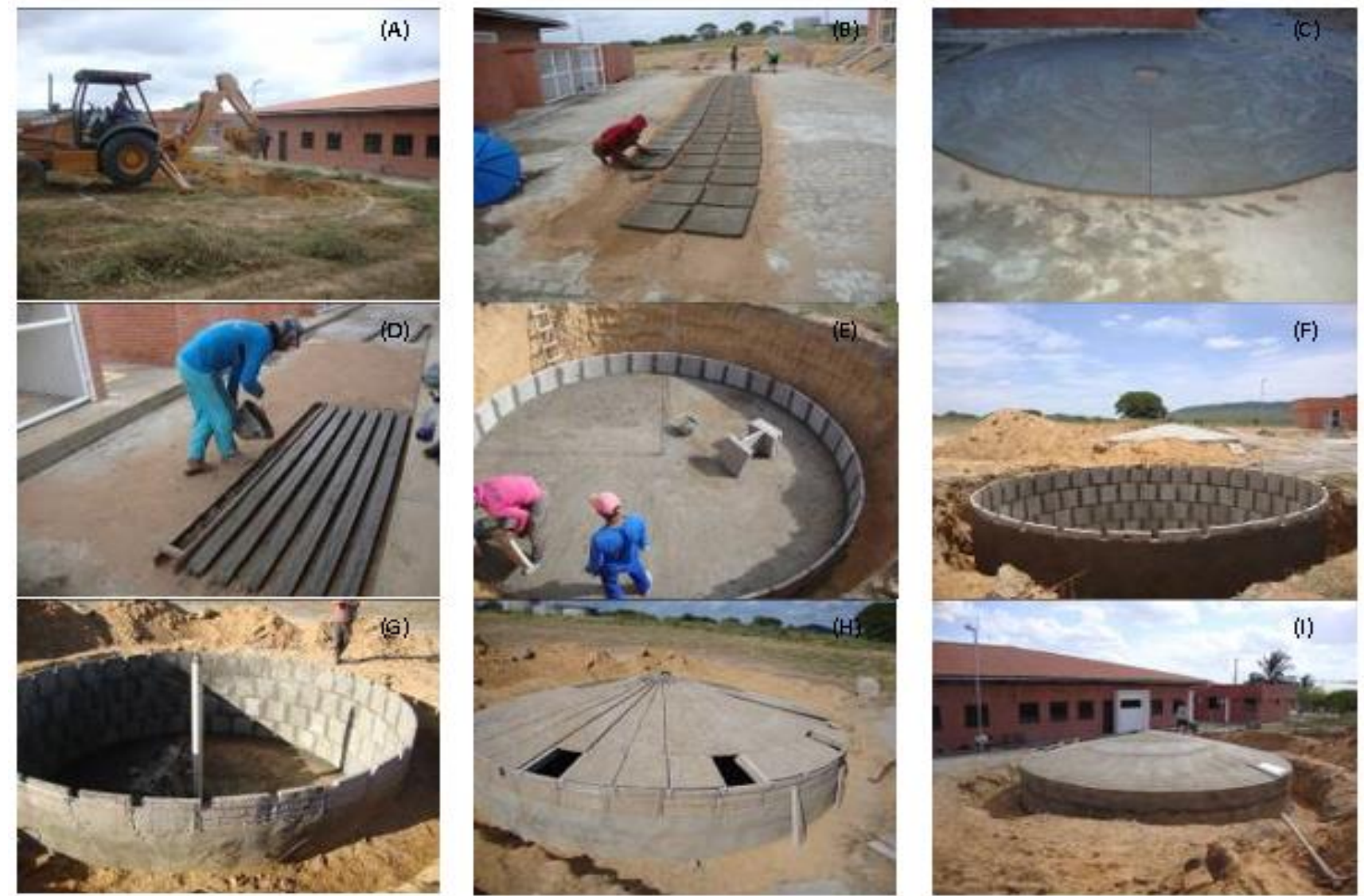

Figura 2: Construção das cisternas de produção. A - Escavação com círculo demarcado; B - Confecção das placas da parede; C Confecção das placas da cobertura; D - Construção dos caibros; E - Início da construção da parede e visão da dase da cisterna n segunda concretagem; F - Visão da parede construída; G - coluna central moldada em tubo PVC; H - Posicionamento das placas da cobertura; I - Cisterna finalizada.

\section{RESULTADOS E DISCUSSÃO}

No ano de 2015, três foram os meses em que o volume precipitado superou a capacidade de armazenamento das cisternas construídas, mediante a área de captação utilizada (Figura 3). A precipitação total do ano de 2015 foi de $705 \mathrm{~mm}$, superando a média anual da cidade em 130,2mm. O potencial de armazenamento de água por meio das duas cisternas construídas foi 566.400 Litros/ano de 2015.
A estrutura montada serviu como demonstração para comunidade interna e externa do campus. Diariamente, cerca de 1.200 alunos matriculados no campus visualizaram a estrutura que foi estrategicamente montada em local de fácil visibilidade na via de entrada e saída do campus. Com frequência, aulas práticas puderam ser realizadas, permitindo uma abordagem prática de conteúdos relacionados a captação, uso e manejo da água da chuva na produção agrícola, os quais são minimamente explorados nas usuais literaturas do ensino agrícola do país. 


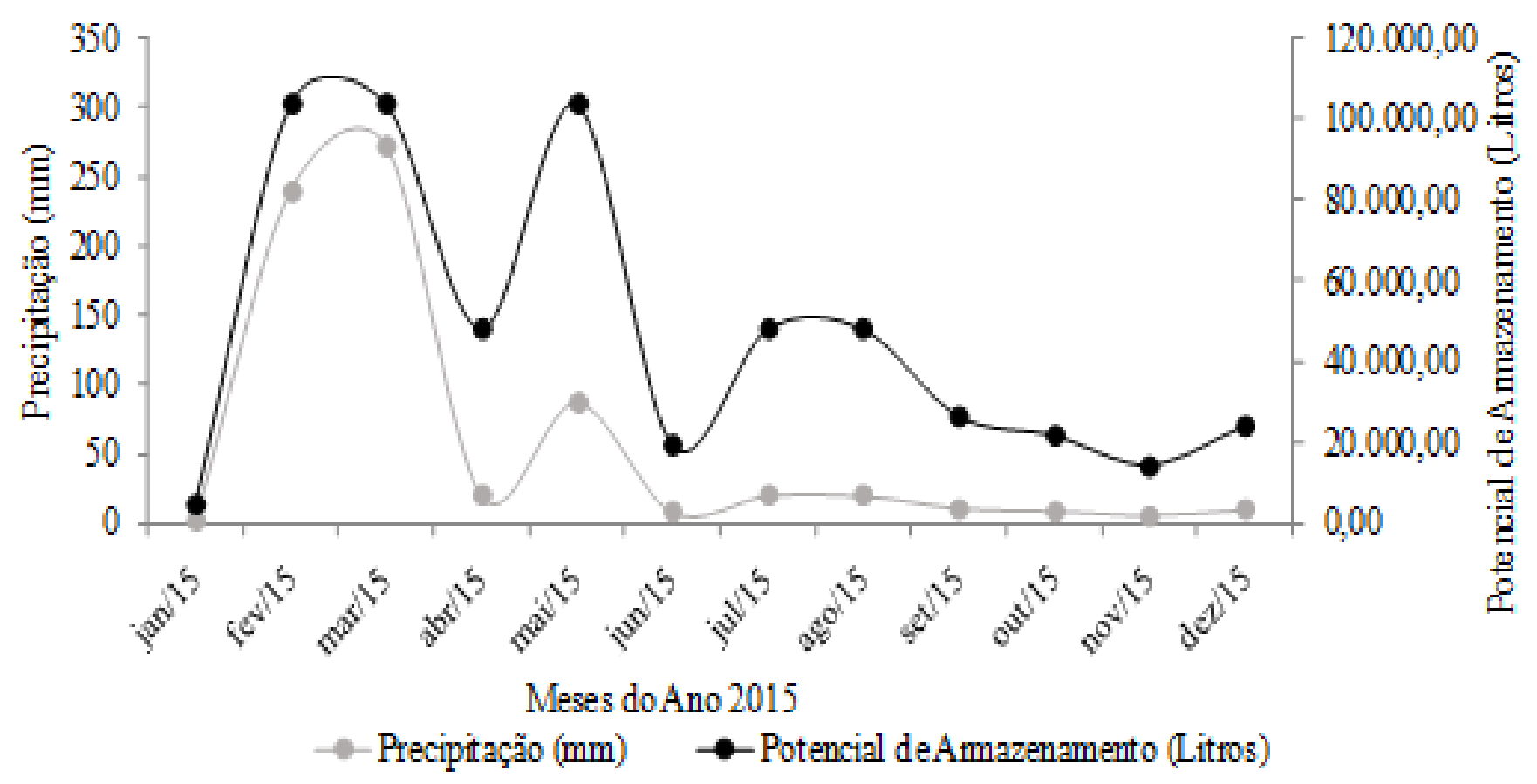

Figura 3: Volume de chuva precipitado e armazenado durante o ano de 2015.

Fonte: Autores, (2016).

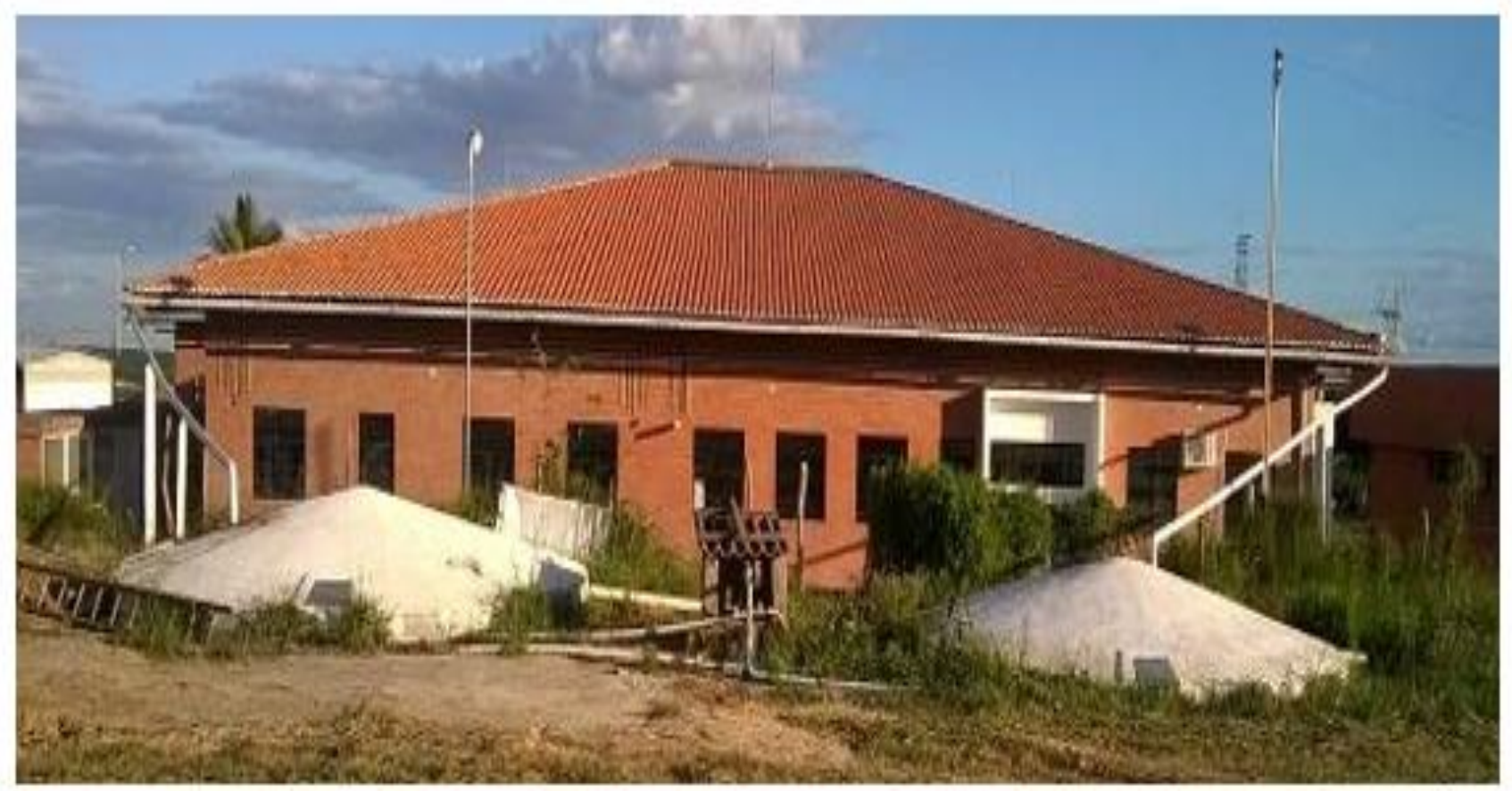

Figura 4: Vista do sistema de captação e armazenamento de água da chuva montado.

Fonte: Autores, (2016).

Após a chuva de março de 2015, foi possível em abril do mesmo ano, realizar um dia de campo com agricultores, professores e alunos do curso de Licenciatura em Ciências Agrárias (LICA) do IF Baiano - Campus Senhor do Bonfim, totalizando 115 participantes, onde na oportunidade, foi implantada de forma participativa, uma unidade de plantio de umbú gigante e manga (Figura 5). As culturas passaram a ser irrigadas minimamente via sistema por gotejamento com a água captada da chuva, visando manter as plantas vivas para realização de aulas práticas e ações de extensão. Realizou-se dois cursos de manejo e sistemas de irrigação de baixo custo; uma oficina para uso de água da chuva em sistema hidropônico de baixo de custo e um curso de uso de biofertilizantes na agricultura. 


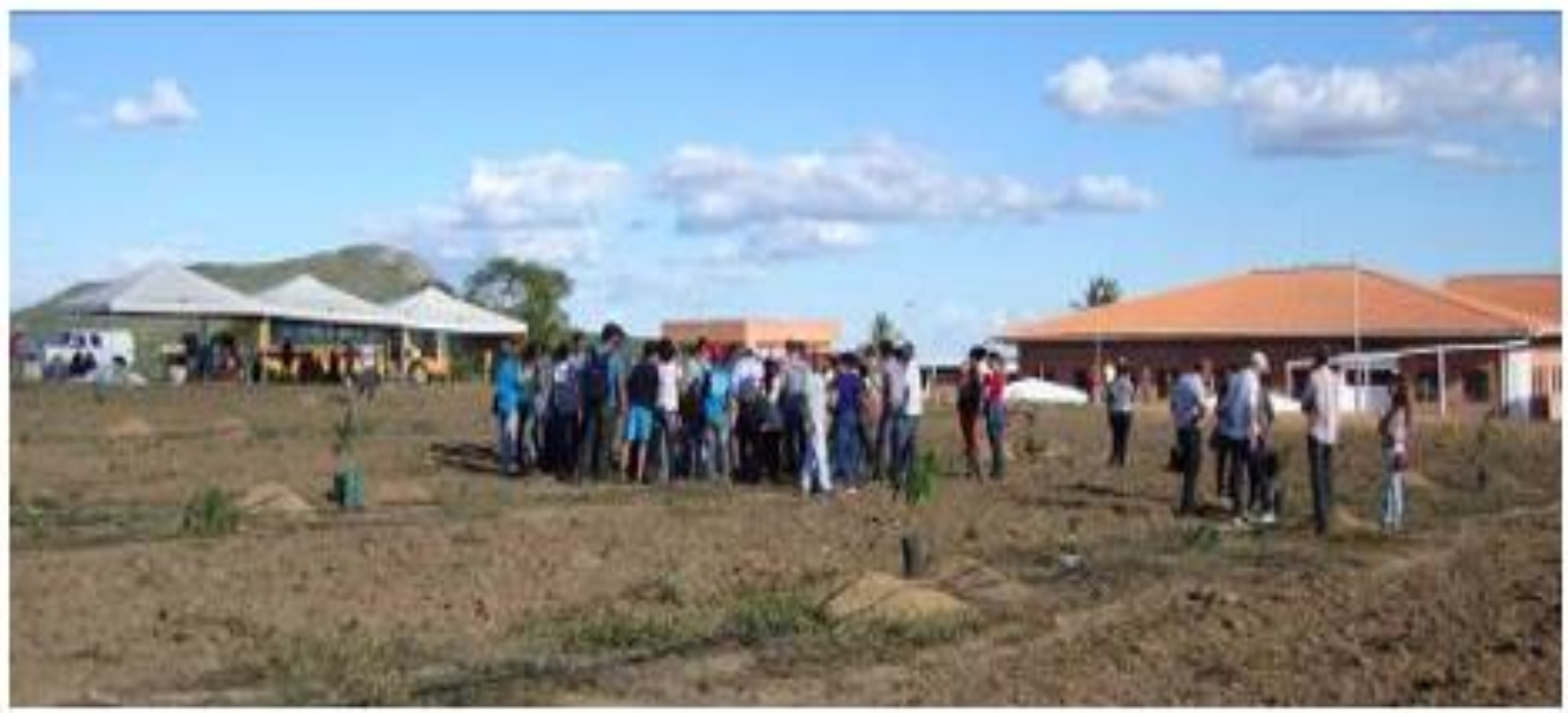

Figura 5: Realização de Dia de Campo com plantio de mudas de umbú gigante e manga de forma participativa. Fonte: Autores, (2016).

Após a chuva de maio de 2015, iniciou-se a implantação de dois experimentos na área: um com objetivo de definir valores de demanda de água do tomateiro para condição de solo coberto e descoberto, outro, visando definir estratégias para irrigação deficitária em quatro variedades de palma forrageira (Figura 6). Tais experimentos são conduzidos por estudantes de pósgraduação (mestrado e doutorado) acompanhados de alunos do curso de LICA bolsis tas de iniciação científica.
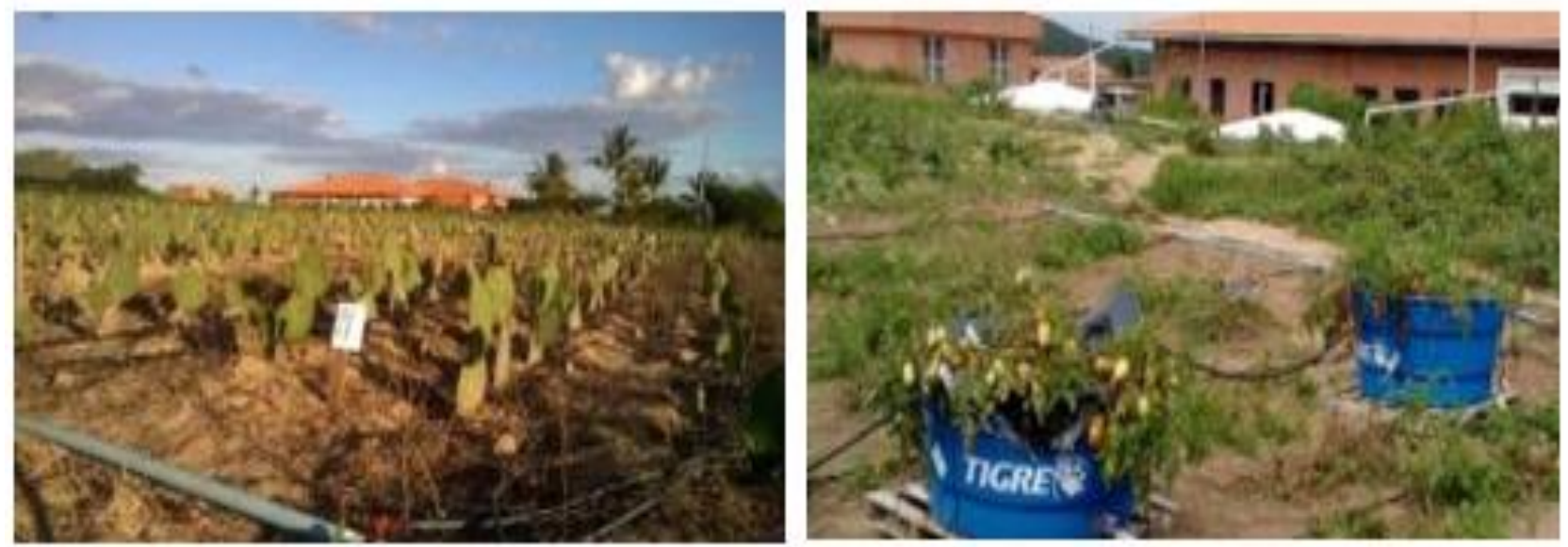

Figura 6: Experimentos montados após montagem do sistema de captação e armazenamento e água da chuva.

Fonte: Autores, (2016).

O presente estudo de caso demonstra, com exemplos, as possibilidades viabilizadas pela implantação de uma unidade didática-experimental com uso de técnicas de captação e armazenamento de água da chuva. Portanto, espera-se que o trabalho sirva como apoio para instituições de ensino localizadas distante de fontes hídricas, que ofertam ensino agrícola, mas que não exploram as diversas possibilidades geradas pela oferta de água, sobretudo no que diz respeito à necessidade de ajuste e aperfeiçoamento do conteúdo pedagógico de algumas disciplinas. Por menor que seja a área de captação, é permitido ao educador inovar sua rotina escolar e experimentar a resolução de problemas aplicados a realidade local.

\section{CONCLUSÕES}

A unidade de captação e armazenamento de água da chuva em instituição de ensino localizada distante de fonte de água viabilizou ações que possibilitam:

- formação de alunos fugindo de pacotes tecnológicos prontos, não havendo necessidade de uso da literatura usualmente 
relacionadas nos projetos pedagógicos de cursos de Licenciatura em Ciências Agrárias;

- abordagem prática de conteúdos não explorados nas usuais literaturas do ensino agrícola do país.

- envolvimento da comunidade externa no processo de ensino-aprendizagem;

- ajuste do processo formativo de alunos do curso de Licenciatura em Ciências Agrárias, envolvendo-os na observação e resolução de problemas locais;

- integrar pesquisa e extensão ao ensino de Ciências Agrárias, especificamente nas disciplinas estatística experimental e irrigação.

\section{REFERÊNCIAS}

[1] Parizotto, I. Coelho, Eugênio Ferreira; Silva, Alisson Jadavi Pereira da. Unidades de Observação Irrigadas Contribuem para a Autonomia Alimentar de Agricultores Familiares do Semiárido Baiano. In: X Congresso da Sociedade Brasileira de Sistemas e Produção, 2014, Foz do Iguaçu. Enfoque Sistêmico e Agricultura Familiar na Construção do Desenvolvimento Sustentável, 2014.

[2] Aquino, J. R.; Lacerda, M. A. D. Magnitude e condições de reprodução econômica dos agricultores familiares pobres no semiárido brasileiro: evidências a partir do Rio Grande do Norte. Revista de Economia e Sociologia Rural. vol. 52, p 167188, 2014. 